\title{
Improving the safety of railway subgrade when it is strengthened using soil-cement elements
}

\author{
Vitalii Krysan ${ }^{1}$, Volodymyr Krysan ${ }^{2}$,Volodymyr Petrenko ${ }^{3}$, Oleksii Tiutkin ${ }^{3}$, and Volodymyr Andrieiev ${ }^{3, *}$ \\ ${ }^{1}$ Head of REMBUD LLC Dnipro, Ukraine \\ ${ }^{2}$ Head of PARITET LLC, Dnipro, Ukraine \\ ${ }^{3}$ Dnipro National University of Railway Transport named after Academician V. Lazaryan, Lazaryan str., 2, Dnipro, Ukraine
}

\begin{abstract}
The article identifies the main parameters of the drilling-mixing technology, which is the most effective in fixing weak soil bases during the construction and restoration of transport, industrial and civil structures. The difference of the technology developed by the authors is that the strengthening process is carried out at low pressure $\left(\begin{array}{lll}0.15 & \ldots & 0.25 \mathrm{MPa}\end{array}\right)$. The relevance of the research is that the proposed technology requires less cost with high rates of restoring the strength of soil foundations. To prove the high quality of the technology, laboratory studies were carried out to determine the optimal characteristics of the soil-cement element, as well as the proportions and composition of the fixing solution. The dependences of the strength of soil-cement elements in the air-dry condition with cement content from $7 \%$ to $23 \%$ with water-cement ratio in solution $1 / 0.3$ and with cement content from $13 \%$ to $37.5 \%$ with water-cement ratio in solution 1/0,6. During the experimental-industrial studies of the author's technology, the embankment was constructed with the soil-cement-reinforced elements for the access road approaches at one of the facilities in Kirovograd region, which ensured safety in the operation of a complex transport structure.
\end{abstract}

\section{Introduction}

With the transition of railways to increased train speeds, forecasting of the stress-strain state of the subgrade becomes relevant.

The instability of the subgrade of railways may depend not only on operational factors, poor properties of soils, its components. Therefore, the transition to high-speed trains $(200 \mathrm{~km} / \mathrm{h}$ and more) requires a thorough study of the condition of the subgrade and its corresponding reconstruction.

The main task is to find engineering solutions aimed at improving the operational reliability of earthworks and the normal provision of a long service life. Scientific and engineering proposals must meet modern requirements for the operation of railways, since the transition of railways to increased speed without modernization and partial or complete restructuring of engineering structures is impossible. There are no references to solving this problem in the world.

The following basic requirements are imposed on the subgrade of railways:

- it must be strong, stable, reliable and durable;

- all surfaces of the subgrade, devices in the right of way must be planned and protected so that atmospheric water does not stagnate anywhere, and its maximum outflow to the side or special drainage structures are ensured, and the flowing water does not erode the slopes and base;
- the construction of the subgrade should provide minimal costs for its construction and operation with the maximum possible mechanization of work.

In addition, the subgrade must be interconnected with the highway, maintainable, and ensure long-term operation when skipping modern and promising types of rolling stock at maximum train speeds and rated load.

The main element of the subgrade, a roadbed, takes the greatest load from the rolling stock. The roadbed and its structures should ensure the safety of trains with given loads and speeds at the set load capacity. The roadbed, its elements and structures must comply with the standards of strength and stability during the entire period of operation.

The reliability of the roadbed is determined by the elastic characteristics, which in turn determine the stressstrain state of the elements of the track superstructure and its durability. As it is known, only a roadbed, which has residual deformations, is attributed to a deformed one, and elastic deformations, which have a sufficiently small value, are not taken into account. But residual deformations should not be allowed and the subgrade should be such that under no force or climatic actions such deformations would arise. This determines the reliability and stability of the roadbed.

The characteristic determining the quality of the subgrade is its elasticity. The distribution of stresses in the subgrade is rather uneven. Herewith, the unevenness of the stress state of the rails due to the non-uniform

* Corresponding author: avs_diit@ukr.net 
elasticity of the track can reach up to $60-70 \%$. The structure of the subgrade soil determines the nature of the stress distribution. The subgrade is considered sound if it does not have intense residual deformations. The stresses from the train load are unevenly distributed over the cross section, which indicates the presence of shear static and dynamic stresses. Due to the increased intensity of the subgrade loading, the condition of the track deteriorates. In some cases, there is a concentration of increased deteriorations of the track and the failure of its elements. The reason for this condition may be decreased subgrade elasticity. When overhauling the subgrade, it is necessary to comply not only with its strength and stability, but also with the elastic characteristics. Their value is set depending on the influence on the track elastic state both by absolute value and by the ranges of oscillations.

Deformations of the subgrade and its structures arise due to:

a) Insufficient bearing capacity of the soil from which it is built;

b) Non-conformity of the track superstructure strength and the load from the rolling stock;

c) Insufficient protection of the subgrade soil from the adverse effects of climatic and geotechnical factors.

As is known, oscillations arise in the railway roadbed under the influence of train load, the amplitude of which depends on many factors, including train speed and load on the rolling stock axle.

The experience gained during the construction and operation of high-speed rail lines shows that the forces transmitted by rolling stock to the subgrade at speeds exceeding $160 \mathrm{~km} / \mathrm{h}$ are not very different from those transmitted at speeds of $140-150 \mathrm{~km} / \mathrm{h}$. But as the speed rises, the subgrade vibrations increase dramatically.

Improper use of weak soils for the construction and further operation of railway embankments from the same soil leads to a loss of bearing capacity of railway embankments. In turn, this may lead to non-compliance with the rail traffic safety requirements[3]. Therefore, an increase in the carrying capacity of the subgrade soil directly leads to an increase in safety in railway transport.

One of the most promising technologies for securing weak soil bases during the construction and restoration of transport, industrial and civil structures is the drillingmixing technology. Its main product is soil-cement elements that strengthen and reinforce the soil foundation.

The soil-cement element technology consists in mechanical mixing and additional hydromonitor development of a certain soil volume. At the same time, there is an additional high-quality mixing of the soilcement mix, which forms the body of the soil-cement element. Using the jet-mixing bit invented by us (declarative patent for invention No. 62868A), it is possible to perform hole deepening for the element and lift the tool with rotation without changing the direction of rotation of the working tool. As a result, a soil-cement body is formed in the soil thickness, while the moisture content of the soil massif does not affect its formation. Soil-cement elements can be created in both dry and water-saturated soils.
One of the most important technological factors in the drilling-mixing technology of rock consolidation is the selection and use of fixing solutions. This is due both to the specifics of the proposed method and the requirements for fixed rocks when solving various construction problems.

The fixing solutions should have:

1) Ability to form new soil-cement structures with desired physical, mechanical and filtration properties;

2) Ability not to exfoliate during jetting;

3) Ability to harden under water;

4) Setting time, providing the necessary conditions;

5) Ensuring the implementation of the technological process of preparation and jetting;

6) Satisfactory miscibility with the ground being fixed;

7) Necessary filtrate loss after the process completion;

8) Sufficient uniaxial compression strength.

Soil-cement elements, if necessary, can be reinforced in the upper part, and for their entire length. As reinforcement, reinforcing bars, space framework, Ibeams, channel bars or other structural materials can be used depending on the purpose. Moreover, the reinforcement can be performed in the first hours before the soil-cement material sets, by ordinary immersion of reinforcing elements. The technology of soil consolidation by this method is aimed at increasing the carrying capacity of the subgrade body, which in turn leads to rail traffic safety.

\section{Methodology}

When checking the operated embankments for reliability and stability using existing standards, it was established that most of them meet the requirements and are aimed at improving traffic safety. At the same time, restoring activities only support the subgrade in a more or less stable state. It has not been possible yet to reduce the number of deformed sections and their share remains within $10-12 \%$ of the total length of lines operated, therefore large sums are spent annually on the subgrade repair. Obviously, the main cause of subgrade deformations is the growth of the dynamic load from trains, moving objects. Accounting for the dynamic impact of train load in the work of the subgrade is one of the most important areas of research in transport geomechanics and geotechnics [1,2]. All researches can be divided into 5 directions.

The first direction is connected with the determination of the dynamic characteristics of soils and, first of all, the strength properties of soils.

Another direction is experimental simulation and first of all centrifugal testing of models.

The third direction may be field studies.

The fourth direction is vibration diagnostics, which can be complemented by test boring and drilling.

The fifth direction is the subgrade calculations taking into account the dynamic impact. Dynamic calculations are divided into 3 parts:

1. Subgrade stability calculations.

2. Elastic settlement calculations.

3. Roadbed residual deformation calculations. 
On the basis of the analysis performed, we proposed a technique for studying the subgrade state by the mathematical modeling method using field and laboratory studies of soils that are available to the personnel of geotechnical stations of railways. Herewith, the subgrade state study can be carried out promptly, taking into account specific conditions, and with minimal costs. In addition, the presence of the calculation complex in the railway management system will allow changing the approach of geotechnical personnel to solving the problems of improving traffic safety and reliability of operation of the subgrade and track facilities.

Currently, a number of ways have been developed to strengthen weak soils with the creation of soil-cement elements, including injection of compressed air and water under high pressure $(50 \ldots 70 \mathrm{MPa})$ into the foundation. The essence of the technology developed by the authors is that the strengthening process is carried out at the sufficiently low pressure (0.15 ...0.25 MPa). In this case, the soil destructing is performed by a special device - a jet-mixing bit (declaration patent for invention No. 62868) [6]. Thus, the process of dispersing and mixing the soil is the simultaneous impact of the bit and the jet of water-cement mixture, which is fed through the hole in the monitor.

The setup of soil-cement elements can be made instead of footing excavation and arrangement of the groundbed on the subsiding soils, bedding for various purpose foundations, as well as during the embankment restoration. Portland cement, slag portland cement (DSTU B.V.2.7.46.96), sulphate-resistant cement (DSTU B.13.07-85-99) of grade 400 or higher are used for the construction of soil-cement elements. To ensure the mixture mobility and adjust the setting time, plasticizers, superplasticizers and retarders are introduced in an amount necessary to ensure the design parameters $(1 \ldots 4 \%$ of the cement volume). Watercement ratio is selected depending on the engineeringgeological conditions, porosity and soil moisture, its particle size distribution, as well as based on the results of work on the experimental plot[4].

\section{Findings}

In order to determine the optimal characteristics of the soil-cement element, we carried out the laboratory studies of the proportions and composition of the fixing solution, as well as the ratio of its quantity in the volume of the test soil (collapsing and loess loam) [5]. The soil characteristics determined by engineering and geological surveys are shown in Table 1 .

Table 1. Soil characteristics

\begin{tabular}{|l|l|l|l|}
\hline \multicolumn{4}{|l|}{ Natural condition of soil } \\
\hline$\gamma=14.48 \mathrm{kN} / \mathrm{m}^{3}$ & $\varphi=24^{\circ}$ & $\mathrm{C}=23.0 \mathrm{kPa}$ & $\mathrm{E}=13.0 \mathrm{MPa}$ \\
\hline Water saturated soil & & \\
\hline$\gamma=17.94 \mathrm{kN} / \mathrm{m}^{3}$ & $\varphi=13^{\circ}$ & $\mathrm{C}=6.0 \mathrm{kPa}$ & $\mathrm{E}=3.0 \mathrm{MPa}$ \\
\hline
\end{tabular}

where: $\gamma$ - Soil density; $\varphi$ - angle of internal friction; C - Specific adhesion; E - strain module.
To obtain optimal characteristics, we conducted two series of experiments to determine the strength characteristics of soil-cement at different ratios of water, cement and plasticizer [7]. For this purpose, there was prepared a fixing solution of water and cement with the addition of a plasticizer, preventing the mixture from splitting, in a special container. The volumetric method allowed measuring the required amount of fixing solution and soil, that was mixed in a steel cylindrical vessel until a homogeneous composition of the mixture was obtained. In the first series of experiments, the fixing solution was prepared at the rate of $300 \mathrm{~kg}$ of cement per one cubic meter of water. The plasticizer was added at the rate of $2.5 \mathrm{~kg}$ per $1000 \mathrm{~kg}$ of cement. The ratio of soil and fixing solution was 1/1, 1/2, 1/3, 1/4.

The results of determining the strength of soil-cement elements in the air-dry condition with a cement content of $7 \%$ to $23 \%$ with a water-cement ratio in the solution $1 / 0.3$ and with a cement content of $13 \%$ to $37.5 \%$ with a water-cement ratio in the solution $1 / 0,6$ are presented in Figure 1.

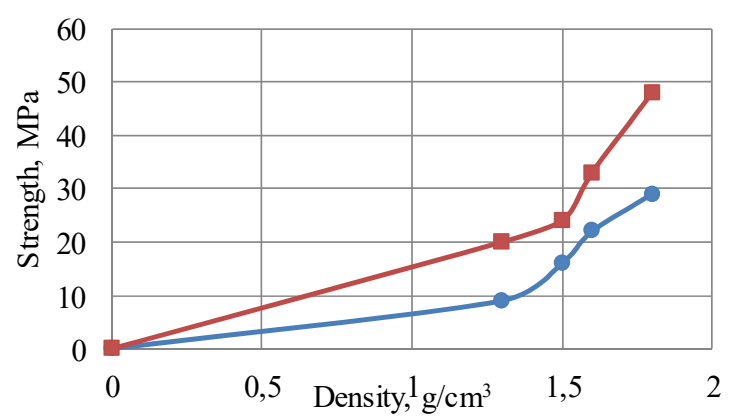

Fig. 1. Soil-cement element strength dependency graph:

$\rightarrow \quad$ Row 1 - with the cement content from $7 \%$ to $23 \%$;

$\rightarrow \quad$ Row 2 - with the cement content from $13 \%$ to $37.5 \%$

The experiments showed the increased strength of the samples with the rise in cement percentage and, accordingly, their density. Herewith, in the second series of experiments, the same soil was taken (collapsing and loess loam), and the fixing solution was prepared at the rate of $600 \mathrm{~kg}$ of cement per one cubic meter of water. As in the first experiment, the plasticizer was added at the rate of $2.5 \mathrm{~kg}$ per $1000 \mathrm{~kg}$ of cement. The ratio of the soil and the fixing solution was taken, as in the first experiment, 1/1, 1/2, 1/3, 1/4 (see Fig. 1, curve 2).

Changing the water-cement ratio and obtaining the characteristics of the soil-cement element while reducing the amount of water in the solution was carried out in order to obtain solutions that, when used, would not soak the soil outside the body of the soil-cement element, which would prevent the development of subsidence phenomena in loess soils. The experiment confirms the increase in the strength of the samples with increased percentage of cement. According to the graphs of the dependences obtained we can predict the strength of the soil-cement element when the percentage of cement changes for its other ratios.

A large class of structurally unstable soils is composed of loess subsidence soils, in which a structural disruption with the occurrence of significant subsidence occurs when they are soaked under load. 
Drawdowns are called local fast-flowing vertical deformations of soils caused by a sharp radical violation of the structure and accompanied by a partial or complete loss of resistance to disturbed soil masses, and with excessive moisture - squeezing soils to the sides.

The practice of building on loess soils has shown that subsidence can reach significant values. The property of loess soils to lose the stability of their structure upon wetting determines the peculiar construction qualities of these soils that require special consideration.

Loess soils occur in a significant part of Ukraine. For the practice of construction, it is very important to be able to distinguish subsidence loess soils from ordinary soils, to know the peculiarities of the mechanical properties of subsidence soils and to foresee the influence of these properties on the structures under construction.

The mixing process cannot be considered only as mechanical mixing of components in a certain volume of the material. Mixing should ensure optimal conditions for the physicochemical processes of the formation of the technological properties of soil-cement elements.
Due to the fact that the fixing solution is supplied to the well bottom under pressure of $0.1 \ldots 0.3 \mathrm{MPa}$, and flows out of a small diameter nozzle, turbulent motion of soil particles occurs in the flow, which move randomly not only in the direction of flow, but also perpendicular to it. This process is accompanied by interpenetration of the particles from one layer into another and the number of their collisions increases, which creates a more uniform structure of the soil-cement element. In all cases, when performing work, the fixing mixture jet flows out of the nozzle into the medium consisting of particles of the soil destroyed up to certain parameters and the fixing substance existing there.

To determine the zone of penetration of the fixing solution into the original soil during the formation of soil-cement elements, in the experimental plot of works, soil was sampled in the immediate vicinity of the soilcement element. Then we determined the soil characteristics.

In addition, these laboratory studies were compared with the studies conducted for the construction project development. The results of these studies are presented in Table 2.

Table 2 - Results of field studies of soil properties

\begin{tabular}{|l|c|c|c|c|c|c|c|}
\hline \multirow{2}{*}{ Soil parameters } & \multicolumn{3}{c|}{$\begin{array}{c}\text { Sampling from the mass wall at a } \\
\text { distance of 50 mm from the } \\
\text { soil-cement element }\end{array}$} & \multicolumn{2}{c|}{ Control samples } & \multicolumn{2}{c|}{$\begin{array}{c}\text { Soil survey } \\
\text { characteristics }\end{array}$} \\
\cline { 2 - 9 } & 1 & 2 & 3 & 4 & 1 & 2 & 1 \\
\hline Natural moisture & 0.19 & 0.17 & 0.18 & 0.19 & 0.09 & 0.18 & 0.14 \\
\hline Soil density, g/cm & 1.53 & 1.56 & 1.63 & 1.62 & 1.46 & 1.61 & 1.72 \\
\hline Porosity & 0.52 & 0.50 & 0.48 & 0.49 & 0.49 & 0.49 & 0.44 \\
\hline Relative subsidence with control soaking & 0.046 & 0.046 & 0.0355 & 0.0463 & 0.0411 & 0.0308 & 0.0157 \\
\hline Elasticity modulus E, MPa & 1.98 & 2.38 & 2.63 & 3.00 & 3.79 & 3.09 & 2.049 \\
\hline Angle of internal friction $\varphi$, degrees & 27 & - & 25 & - & 29 & 27 & 24 \\
\hline Specific cohesion $\mathrm{C}, \mathrm{MPa}$ & 0.010 & 0.016 & 0.016 & - & 0.014 & 0.0093 & 0.0155 \\
\hline
\end{tabular}

During the experimental-industrial studies, the embankment was constructed with the soil-cementreinforced elements for subgrade approaches. The width of the embankment on top was 13 meters, and at the bottom it was variable, from 25 to 40 meters, height - 9 meters, length - more than 1000 meters. At present, the embankment settles, and its slopes, washed out by storm and melt waters, are sagging.

An engineering-geological element (EGE) should be considered an engineering-geological body, represented by one rock, statistically uniform in some indicator of properties, selected in each case based on the requirements of the calculation of a particular engineering-geological process that is performed during the design of the structure.

The volume and configuration of the IGE is established, taking into account geological data and data on the type, design and technical characteristics of the structure. When calculating the settlement of a structure (the compaction value of the geological environment at its base), the NE active zone should be divided into engineering-geological elements, i.e., engineeringgeological bodies, statistically uniform in modulus of general deformation - compressibility factor. When calculating the filtration, the filtration zone should be divided into IGE, statistically uniform in value of the filtration coefficient.

To obtain the soil characteristics of the embankment, we carried out the geological engineering surveys. It was established that the embankment body consists of eight layers of soil, most of which are not compacted and according to their characteristics by DBN B.2.3-4-2000 cannot be the body of the embankment. Relatively homogeneous layers have a thickness of from $0.5 \mathrm{~m}$ to 3.5 $\mathrm{m}$, not maintained in plan. In addition, at the base of the embankment there is topsoil with a thickness of up to 90 $\mathrm{cm}$, represented by black loam, solid, with an admixture of organic matter. Furthermore, at the base of the embankment there is a topsoil and a layer of loess subsiding soils, which, when soaked, will give a subsidence of up to $40 \mathrm{~mm}$.

From the survey materials it follows that the heaping of the embankment is performed without proper compaction with soils of different composition with a large amount of organic matter. It should also be noted that a drainage layer should be arranged at the embankment bed, which was absent.

It is known during backfill operation the soil moisture in it is higher than in the adjacent massif. For this reason, at the contact of the embankment with its bed, the soil moisture will rise and the embankment bed 
will subside. In addition, the physico-mechanical characteristics of loess deteriorate, which would entail the settlement of the embankment. Given that the height of the embankment reaches 9 meters and it varies along the length of the profile, the settlements will be extremely uneven. The soil skeleton creep is the decisive factor in the progress of the deformation of the embankment over time. Transport flow, which creates dynamic loads, is also a factor that increases the intensity and amplitude of the embankment settlements during vibration creep.

Based on the foregoing, guided by technical, economic and environmental considerations, it was proposed to reinforce the existing embankment and its foundation with a system of soil-cement elements ensuring the transfer of permanent and temporary loads to the non-subsiding layer (Fig. 2).

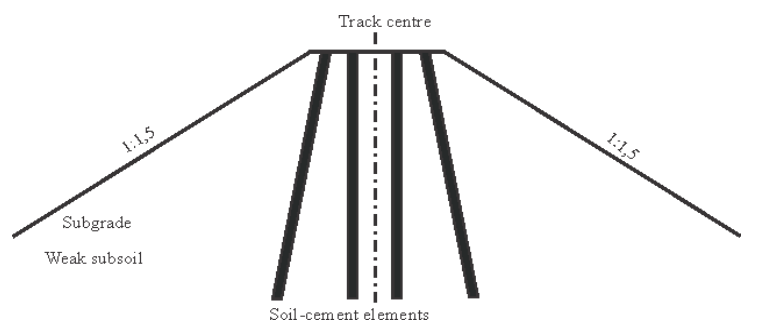

Fig. 2. Scheme of reinforcement of the existing railway embankment and its foundation with soil-cement element system

As a result of industrial experimental studies performed on the considered object, there were obtained the following technological parameters of soil-cement elements, created with the help of drilling-mixing technology of rock consolidation (Table 3 ).

Table 3. Technological parameters of element formation using the drilling-mixing technology

\begin{tabular}{|c|c|c|c|c|c|}
\hline $\begin{array}{c}\text { Engineering } \\
\text { geological element } \\
(\text { EGE) }\end{array}$ & $\begin{array}{c}\text { Monitor } \\
\text { immersion } \\
\text { speed } \\
v, \mathrm{~m} / \mathrm{min}\end{array}$ & $\begin{array}{c}\text { Monitor } \\
\text { rotation } \\
\text { speed } \\
w, \mathrm{rpm}\end{array}$ & $\begin{array}{c}\text { Axle pressure } \\
P, \mathrm{MPa}\end{array}$ & $\begin{array}{c}\text { Soil-cement element } \\
\text { diameter } \\
d, \mathrm{~m}\end{array}$ & $\begin{array}{c}\text { Strength of soil-cement } \\
\text { element for uniaxial } \\
\text { compression } \\
\sigma^{\text {av }} \text { comp }\end{array}$ \\
\hline EGE-2 sand & $1 \ldots 2$ & 30 & $2.5 \ldots 5.0$ & $0.6 \ldots 0.9$ & 0.42 \\
\hline EGE-2a sandy loam & $1 \ldots 2$ & 30 & $2.5 \ldots 5.0$ & $0.9 \ldots 1.04$ & 0.47 \\
\hline EGE-3 sandy loam & $1 \ldots 2$ & 30 & $2.5 \ldots 5.0$ & $0.7 \ldots 0.76$ & 0.52 \\
\hline
\end{tabular}

\section{Conclusions}

As a result of laboratory and experimental-industrial experiments, we established the basic laws of distribution of the physical mechanical properties of soilcement elements. The values of the following characteristics were obtained for similar indicators of moisture and subsidence: increase in the density of soilcement elements and a strain modulus, as well as decrease in their porosity with increased cement content in the experimental sample of the element.

The implementation of the developed method of reinforcing the high ground embankment made it possible to obtain the strengthening soil-cement elements in real volume with diameters increased to $0.6 \ldots 1.0 \mathrm{~m}$ with their high strength.

In the course of experimental-industrial work, we established the possibility of arranging soil-cement elements in soils during railway construction, the foundation of which are subsiding loess soils. This allows to effectively perform work near existing facilities, as well as to carry out reconstruction of railway embankments with increased load on the roadbed, which will improve the railway transport safety.

\section{References}

1. Mitchell, J. K., Willem, Villet C. B., Dimilllo, A. F. Soil Reinforcement for stabilization of Earth Slopes and Embankments Public Roads,. Vol. 48. - No. 3. pp. 88-95 (1984)
2. Elliott, Robert P. Permanent Deformation of Subgrade Soils Fayetteville: Mack-Blackwell Transportation Center, 216 p. (1998)

3. Ginzburg, L. K. Protivoopolznevye sooruzhenija: monografija [Anti-landslide structures: monograph] - Dnepropetrovsk: Lira LTD., 188 p. (2007)

4. Zotsenko, M. L., Vinnikov, Yu. L., Lartseva, I. I., Shokarev B. C., Krysan V. I. Kharakterystyky shtuchnykh tverdykh gruntiv, yaki polipsheni burozmishuval'nym metodom [Characteristics of artificial solid soils, which are improved by the mixing method] Svit geotehniki. - No. 3. - P. 14-18 (2011)

5. Shapoval V.G., Sedin V.L., Shapoval A.V., Morklyanik B.V., Andrieiev V.S. Mekhanika gruntov [Soil mechanics] Textbook. Dnepropetrovsk: Porogi, - 168 p. (2010)

6. Romanenko V. I., Krysan V. I. Mix-drilling bit Declarative Patent for Innovation No. 62868 of 15.03.2007.

7. Petrenko V.D., Pshinko P.O., Tiutkin O.L., Marochka V.V., Kulazhenko E. Yu. Method of subgrade strengthening Patent for utility model No. 114248 of 10.03 .2017$.

8. V. D. Petrenko, O. L. Tiutkin, I. O. Sviatko Estimation of subgrade strengthening influence using soilcement elements Science and Transport Progress. No. 4 (64). - P. 161-168 (2016)

9. D. Ignatenko, O. L. Tiutkin, V. D. Petrenko, A. M. Alkhdour IJCIET, 10(01), (2019) 